\title{
The Prevalence of Rheumatoid Arthritis in the Elderly that attend Pilgrimage Centre, Elele, Nigeria
}

\author{
B. O. Eledo, E. O. Tommy, E. C. Onuoha, K. E. Dunga and O. C. Okamgba
}

\begin{abstract}
This study determined the prevalence of Rheumatoid arthritis in elderly people that attended pilgrimage center, Elele Rivers state, Nigeria. A total of 200 subjects attending the pilgrimage center were examined for Rhematoid Factor using Latex agglutination method. The data was subjected to statistical analysis using Statistical Package for Social Sciences (SPSS) version 16.0. A prevalence of $4 \%$ was seen in the female subjects within the age bracket of 65-80 years and a prevalence of $1 \%$ was seen in the male subjects within the age bracket of 61-70 years. It showed that Rheumatoid arthritis was positive in $5 \%$ of the population and negative in $95 \%$ of the population, which was statistically significant $(\mathbf{p}<0.05)$. In conclusion, there is a significant increase in the overall prevalence of rheumatoid arthritis in elderly subjects that attend pilgrimage center, Elele. Therefore, proper care should be instituted to avoid unnecessary complications associated with this ailment.
\end{abstract}

Index Terms - Aging; Haematological Parameters; Malaria Parasitaemia; Rheumatoid Arthritis.

\section{INTRODUCTION}

Rheumatoid arthritis (RA) is a systemic autoimmune inflammatory polyarthritis with articular and extra-articular manifestations [1]. It is regarded as the most common inflammatory arthritis and has a prevalence of $0.5-1 \%$ in industrialized nations [4], [9]. Rheumatoid Arthritis (RA) has a female to male preponderance of about $3: 1$. It is usually associated with increased morbidity, mortality and cardiovascular events [12], [2], [22]. Rheumatoid Arthritis manifests clinically with joint pain and swelling, significant joint stiffness, constitutional symptoms and impaired quality of life. It is associated with numerous extra- articular manifestations including anaemia, subcutaneous nodules and sicca symptoms [8]. The disease mostly targets the synovial lining of the joints but can also affect other organ systems such as the blood vessels, the lungs and the heart. It can lead to, significant impairment in quality of life, permanent joint damage and disability if untreated.

The onset of Rheumatoid Arthritis is a state of persistent cellular activation leading to autoimmunity and immune complexes in joints and other organs where it manifests. The synovial membrane is the initial site of disease, where swelling and congestion lead to infiltration by immune cells. The progression of RA comes in three phases; an initiation phase (due to non-specific inflammation), an amplification

Published on June 4, 2020.

B. O. Eledo, Federal Medical Centre Yenagoa/Madona University, Elele, Nigeria.

(corresponding e-mail: bewelldiagnosticsyen@gmail.com)

E. O. Tommy, Federal Medical Centre Yenagoa, Nigeria.

(e-mail: edidiongtommy@yahoo.com) phase (due to $\mathrm{T}$ cell activation), and chronic inflammatory phase, with tissue injury resulting from the cytokines, IL-1, TNF-alpha and IL-6 [18]. Tumor necrosis factor alpha $(\mathrm{TNF} \alpha)$ is a pro-inflammatory cytokine that plays a major role in regulating the inflammatory response in rheumatoid arthritis (RA). If TNF release is stimulated by B cell products in the form of RF or anti-citrullinated protein antibodies (ACPA) -containing immune complexes, through activation of immunoglobulin Fc receptors, then RA can be seen as a form of Type III hypersensitivity [7]. People with RA are more prone to risk of myocardial infarction atherosclerosis and stroke [26], [3]. Other possible complications include: pericarditis, endocarditis, left ventricular failure, valvulitis and fibrosis [10].

The most common abnormality of the blood cells is anaemia which results from raised hepcidine levels which is a consequence of chronic inflammation caused by RA. Iron is poorly absorbed and also sequestered into macrophages. The red cells normocytic and normochromic while there is low white blood cell count usually among people with Felty's syndrome with an enlarged spleen and liver. The mechanism of neutropaenia is complex. When inflammation is uncontrolled, there is an increase in platelet count. Test for rheumatoid factor (RF) and anti-citrullinated protein antibodies (ACPAs measured as anti-CCP antibodies) are performed when rheumatoid arthritis is suspected [25]. It is positive in $75-85 \%$, but a negative RF or CCP antibody does not rule out RA, rather, the arthritis is called seronegative, which is in about $15-25 \%$ of people with RA [17].

Rheumatoid arthritis affects between 0.5 and $1 \%$ of adults in the developed world with between 5 and 50 per 100,000 people newly developing the condition each year [21].The age at which the disease most commonly starts in women between 40 and 50 years of age, and for men somewhat later. The prevalence ranged from a minimum of $0.13 \%$ (95\% CI 0.10 to 0.17 ) in Algeria [20], $0.6 \%$ (95\% CI 0.40 to 0.80 ) in the Democratic Republic of Congo [14], to a maximum metaanalysis result of $2.54 \%$ (95\% CI -0.43 to 5.52) in South Africa [15], [24]. The overall rheumatoid arthritis prevalence for South Africa was a meta-analysis of three studies with individual prevalence estimates ranging from $0.91 \%$ [23], $4.35 \%$ [24]), to $5.71 \%$ [15]; with moderate but statistically

E. C. Onuoha, Federal University, Otuoke, Nigeria (nedusiju2015@gmail.com)

K. E. Dunga, Madonna University, Elele, Nigeria.

(koolkinso4u@ymail.com)

O. C. Okamgba, Abia State University, Uturu, Nigeria

(okezieokams@yahoo.com) 
non-significant heterogeneity $\left(\mathrm{I}^{2}=55.7 \%, \quad \mathrm{p}=0.104\right)$. However, one South African study reporting the highest prevalence $(5.71 \%)$ only included adults aged over 65 years.

The rheumatoid arthritis prevalence in rural settings per country ranged from a minimum meta-analysis overall prevalence of $0.07 \%$ (95\% CI -0.06 to 0.19) in South Africa [5], [6],[15], [24] , 0.29\% (95\% CI 0.14 to 0.44) in Egypt, to a maximum of $0.37 \%$ (95\% CI 0.01 to 0.74 ) in Lesotho [16]. Two hospital-based studies, both from urban settings, reported on rheumatoid arthritis prevalence. One study found a prevalence of $0.67 \%$ (95\% CI -0.25 to 1.59 ) among HIVinfected adults attending a clinic in urban Uganda [11] and the other one found a prevalence of $0.1 \%$ (95\% CI 0.05 to 0.16) among HIV-infected adults attending an infectious disease clinic at Mulago hospital in Cameroon [19]. A total of one thousand two hundred and fifteen (1215) patients with rheumatological disorders were seen at the rheumatology unit of Lagos State University Teaching Hospital (LASUTH) during the four-year period. Mean age of the patients was 41.4 years. Test for Rheumatoid Factor (RF) was positive in $78(72.2 \%)$. Anti-CCP was positive in 54 (61.1\%). Report from Democratic Republic of Congo showed that $8.5 \%$ of patients that attended a rheumatology clinic over a three-year period had RA [13].

Improper medication of the elderly once the present with joint pains is a common practice in most localities in Nigeria. These pains might not be as a result of rheumatoid arthritis but can be due to other causes or complications. This study was therefore conducted to determine the prevalence of rheumatoid arthritis in the elderly.

\section{MATERIALS AND METHODS}

\section{A. Study Area}

The target population were the elderly that attend pilgrimage centre, Elele, Rivers state, Nigeria.

\section{B. Study Population}

The study was carried out on 200 elderly subjects that attend the pilgrimage centre.

\section{Inclusion Criteria}

Elderly people that attend the pilgrimage centre. Aged from 60 years and above - male and female Subjects with no history of cardiovascular or autoimmune disease.

\section{Inclusion Criteria}

Subjects less than the age bracket (60 years and below). Subjects with life-threatening diseases were excluded (Human Immunodeficiency Virus (HIV), Cardiovascular Disease (CVD), diabetes etc.).

Those who refused consent.

\section{E. Inclusion Criteria}

Ethical approval was obtained from the ethics committees of Madonna University Nigeria, Elele. The participants were briefed on the objectives and procedure of the study and they were reassured of confidentiality and anonymity. Informed consent was duly obtained from the subjects before commencement of the study. Subjects who were not willing to participate were withdrawn from the study without any negative consequence.

\section{F. Reagents}

S1-Rheumatoid factor (RF) Latex Reagent, S2-Positive control, S3-Negative control were all supplied by L.S. BIOTECH and manufacturer's instructions were strictly followed.

\section{G. Sample Collection}

A standard clean venipuncture technique was used to collect $2 \mathrm{ml}$ of blood from each subject from the anticubital or dorsal vein. It was dispensed into a plain sample container and allowed to clot. The sera from the clotted sample were used for rheumatoid factor investigation.

\section{H. Analytical procedure}

Determination of rheumatoid factor.

Methods:

Latex Agglutination Method (Qualitative method)

Kit supplied by: L.S. BIOTECH

Lot Number: 20180114

Principle:

The latex reagent coated with the Human gammaglobulin (gG). The test specimen (serum) is mixed with RF latex reagent and allowed to react. If $\mathrm{RF}$ is present within detectable levels, then a visible agglutination is observed. If $\mathrm{RF}$ is absent below detectable levels, then no agglutination is observed.

\section{Sample Collection}

One drop of serum was pipetted onto the glass slide using the disposable plastic droppers provided with the kit.

One drop of RF latex reagent was added to the drop of test specimen on the slide, without allowing the dropper tip touch the liquid on the slide.

Using a mixing stick provided in the kit, the serum and RF latex reagent were uniformly mixed over the entire circle on the glass slide.

Immediately a stopwatch was started. The slide was rocked gently, back and forth observing for agglutination macroscopically at two minutes.

\section{J. Sample Collection}

The data generated from the study were analysed using appropriate statistical tool using statistical package for Social Sciences (SPSS) version 16. The data was computed into percentage, and significance variations was carried out using Chi square statistical tool at $\mathrm{p}=0.05$.

\section{RESULTS}

Table I: Is classified according to age groups showing the comparative analysis of rheumatoid arthritis negative in both genders, it showed that there was significant difference $(\mathrm{p}<0.05)$ in subjects within the age brackets of $61-65$ while there was no significant difference $(p>0.05)$ in all other age brackets.

Table II: Is classified according to age groups showing the comparative analysis of rheumatoid arthritis positive in both genders, it showed that 2 male subjects $(0.5 \%)$ within the age brackets of 61-70 were positive while 8 female subjects (4\%) within the age bracket of 65-80 were positive. 
Fig. 1: Showed the overall gender distribution of elderly subjects attending pilgrimage in Elele, Nigeria. It showed that the male subjects were $27.50 \%$ while the females were $72.50 \%$.

Fig. 2: Showed the overall prevalence of rheumatoid arthritis among the elderly that attend pilgrimage in Elele, Nigeria. It showed that rheumatoid arthritis was positive in $5 \%$ of the population and $95 \%$ negative in the population, with a $p$-value of $p=0.000$ showing that there was significant difference.

Fig. 3: Showed the distribution of rheumatoid arthritis positive and negative by males and females on elderly attending pilgrimage in Elele, Nigeria. $4 \%$ of the female population was positive and $68.50 \%$ negative while $1 \%$ of the male population was positive and $26.50 \%$ were negative.

TABLE I: COMPARATIVE ANALYSIS OF RHEUMATOID ARTHRITIS NEGATIVE ELDERLy MALES AND FEMALES ATTENDING PILGRIMAGE IN

\begin{tabular}{|c|c|c|c|c|c|c|}
\hline \multirow{3}{*}{$\frac{{ }_{\text {vyrvwwwrvervwr }}}{\text { Age grade }}$} & \multicolumn{4}{|c|}{ ELELE, NIGERIA } & \multirow{3}{*}{$\begin{array}{l}\text { Chi } \\
\text { square }\end{array}$} & \multirow{3}{*}{ P-value } \\
\hline & Males & & Females & & & \\
\hline & $\begin{array}{l}\text { Number of } \\
\text { respondents }\end{array}$ & $\%$ & $\begin{array}{l}\text { Number of } \\
\text { respondent }\end{array}$ & $\%$ & & \\
\hline $55-60$ & 5 & 2.5 & 10 & 5 & 0.500 & 0.480 \\
\hline 61.65 & 13 & 6.5 & 38 & 19 & 5.538 & 0.019 \\
\hline $66-70$ & 8 & 4 & 19 & 9.5 & 2.571 & 0.109 \\
\hline $71-75$ & 14 & 7 & 32 & 16 & 3.522 & 0.061 \\
\hline $76-80$ & 4 & 2 & 15 & 7.5 & 3.600 & 0.058 \\
\hline $81-85$ & 7 & 3.5 & 20 & 10 & 2.571 & 0.109 \\
\hline $86-90$ & 2 & 1 & 2 & 1 & NA & NA \\
\hline $91-95$ & 0 & 0 & 1 & 0.5 & NA & NA \\
\hline Total & 53 & 26.5 & 137 & 68.5 & 18.375 & 0.000 \\
\hline Qhi square & - & 8.000 & - & 33.771 & - & - \\
\hline P-value & - & 0.238 & - & 0.000 & - & - \\
\hline
\end{tabular}

TABLE II: COMPARATIVE ANALYSIS OF RHEUMATOID ARTHRITIS POSITIVE ELDERLY MALES AND FEMALES ATTENDING PILGRIMAGE IN ELELE,

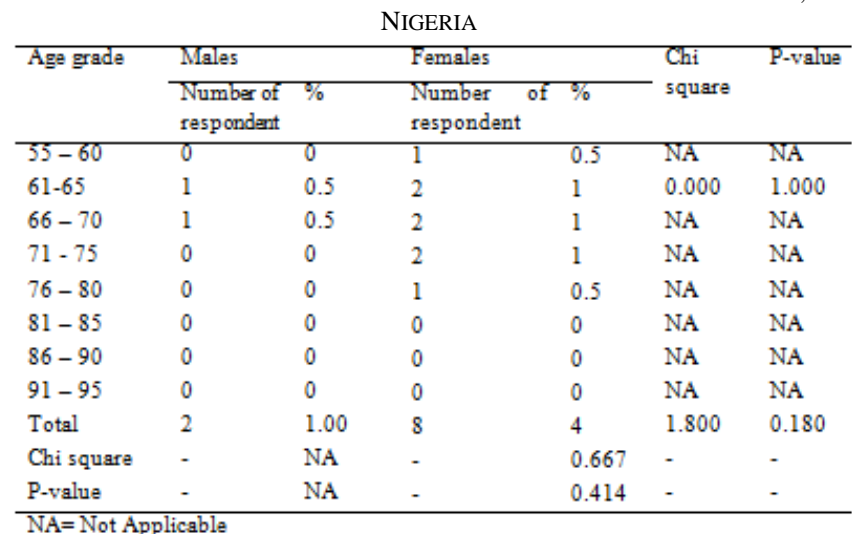

NA $=$ Not Applicable

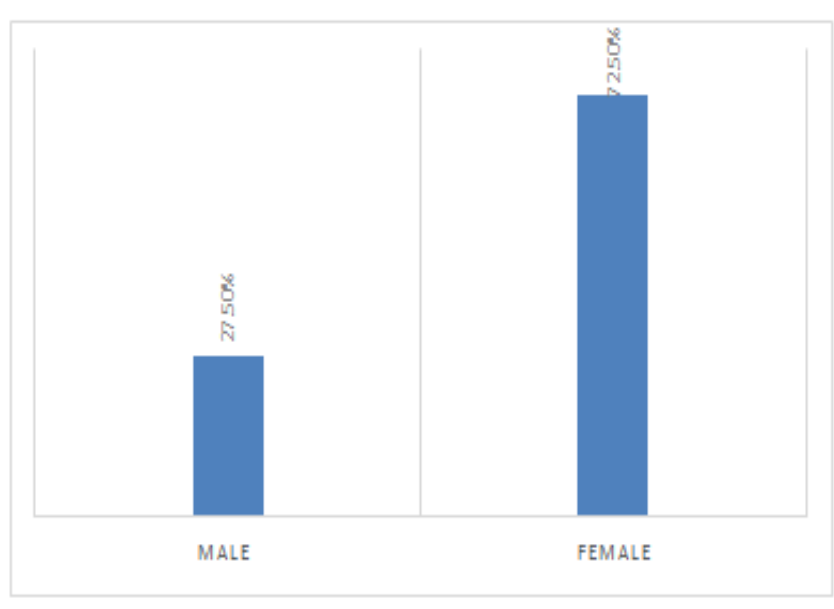

Fig Fig.1: Overall gender distribution of elderly subjects attending pilgrimage in Elele, Nigeria.

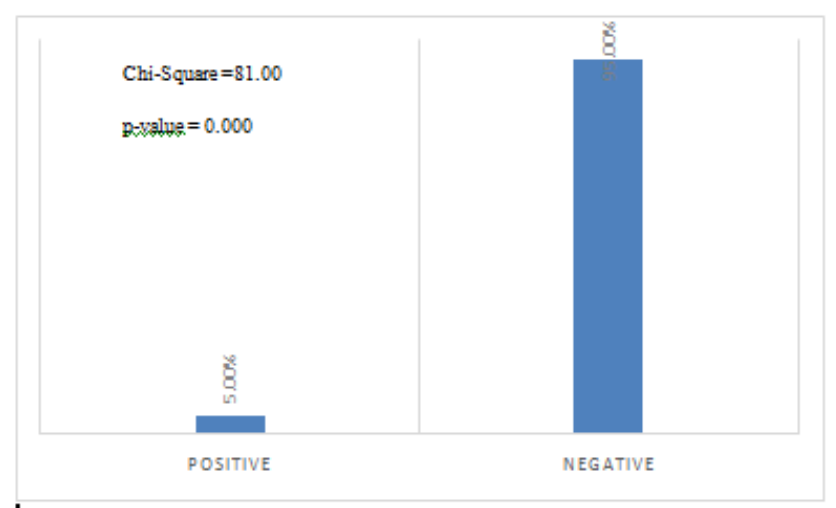

Fig. 2: Overall prevalence of rheumatoid arthritis among the elderly attending pilgrimage in Elele, Nigeria

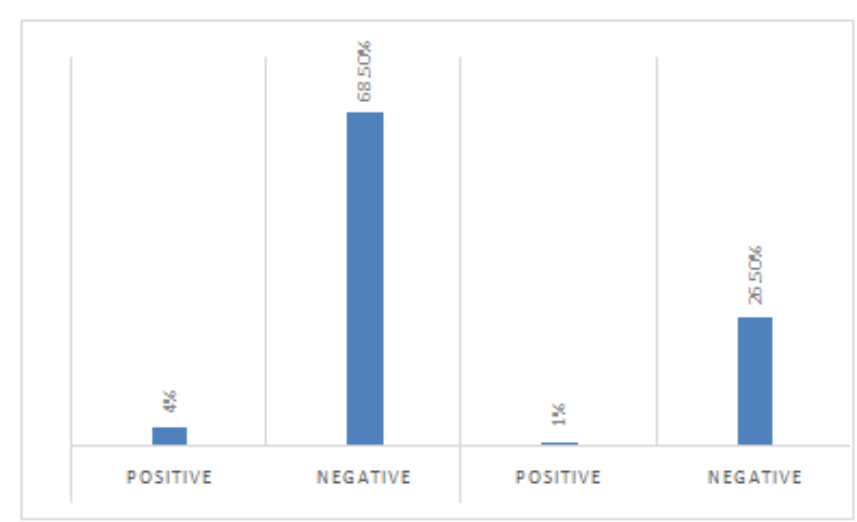

Fig. 3: Distribution of rheumatoid arthritis positive elderly males and females attending pilgrimage in Elele, Nigeria

\section{DISCUSSION}

The result of the study showed that rheumatoid arthritis was positive in $5 \%$ of the population studied. This contrasts with the study by Smolen and his colleagues which showed that rheumatoid arthritis affects between 0.5 and $1 \%$ of adults in the developed world with between 5 and 50 per 100,000 people newly developing the condition each year [21].

The result of the study showed the distribution of rheumatoid arthritis positive in females with $4 \%$ of the female population being positive while only $1 \%$ of the males were positive. This is similar to a study done in Europe showing that rheumatoid arthritis has a female to male preponderance of about 3:1 [12], [2],[22]. 
The result of the study showed that rheumatoid arthritis was positive in $5 \%$ of the population. It contrasted with some prevalence studies which were significantly lower, with a percentage of $0.13 \%$ in Algeria [20], $0.6 \%$ in the Democratic Republic of Congo [14], to a maximum meta-analysis result of $2.54 \%$ in South Africa [15], [23], [24] of 0.07\% in South Africa [5], [6],[15], [24], $0.29 \%$ in Egypt,and $0.37 \%$ in Lesotho [16].

Furthermore, the $5 \%$ prevalence of rheumatoid arthritis obtained in this study is similar to result obtained in South Africa where a prevalence of $5.71 \%$ was found among adults aged over 65years [15]. This agrees with the postulation by [20] that the age at which the disease most commonly starts in women between 40 and 50 years of age, and for men somewhat later.

\section{CONCLUSION}

The results have shown that the overall prevalence of rheumatoid arthritis among the population studied is low. Therefore proper enlightenment should be done to explore other causes of joint pains among the elderly population. Other blood tests such as erythrocyte sedimentation rate and C-reactive protein should be done to differentiate from other causes of arthritis

\section{ACKNOWLEDGMENT}

We appreciate the efforts of staff of Medical Laboratory Department of Madonna University Teaching Hospital Nigeria, Elele, and that of Dr. L.O. Ighedose of Planning \& Statistics Unit of the Federal Medical Centre Yenagoa, Bayelsa State. Also, staff of Bewell Diagnostics LTD Nigeria deserve our strong commendations.

\section{REFERENCES}

[1] O. O. Adelowo, O. Ojo, I. Oduenyi, and C. C. Okwara, "Rheumatoid arthritis among Nigerians: the first 200 patients from a rheumatology clinic", Clinical Rheumatology, vol. 29 (6), pp. 593-597, 2011.

[2] D. Antin-Ozerkis, J. Evans, A, Rubinowitz, R. J. Homer, and R. A Matthay, "Pulmonary manifestations of rheumatoid arthritis", Clinics in Chest Mediciine, vol. 31(14), pp. 451-478, 2010.

[3] J. A. Aviña-Zubieta, H. K. Choi, M. Sadatsafavi, M. Etminan, J. M. Esdaile and D. Lacaille, "Risk of cardiovascular mortality in patients with rheumatoid arthritis: a meta-analysis of observational studies", Arthritis and Rheumatism, vol. 59(12), pp. 1690-1697, 2008.

[4] H. F. Bastian, "Therapeutic strategies in rheumatoid arthritis", Internist, vol. 52 (6), pp. 645-656, 2011.

[5] P. Beighton, L. Solomon and H. A. Valkenburg, "Rheumatoid arthritis in a rural South African Negro population", Annals of Rheumatologic Discussions, vol. 34(2), pp. 136-141, 1975.

[6] S. W. Brighton, A. L. de la Harpe, D. J. van Staden, J. H. Badenhorst and O. L. Myers, "The prevalence of rheumatoid arthritis in a rural African population", Journal of Rheumatology, vol. 15(3), pp. 405408, 1988.

[7] Y. G. Chiu \& C.T. Ritchlin, "Denosumab: targeting the RANKL pathway to treat rheumatoid arthritis" Expert Opinion on Biological Therapy, vol. 17(1), pp. 119-128, 2017.

[8] B. Dowan, R.M. Campbell, L. Zgaga, D. Adeloye and K.Y. Chan, "Estimating the burden of rheumatoid arthritis in Africa", The Journal of Global Health, vol. 2(2), pp. 020-406, 2012.

[9] G. S. Firestein, "Evolving concepts of rheumatoid arthritis", Nature, vol. 423(6937), pp. 356-361, 2003

[10] A. Gupta and\& B. Fomberstein, "Evaluating cardiovascular risk in rheumatoid arthritis", Journal of Musculoskeletal Medicine, vol. 26(8), pp. 481-494, 2009.

[11] M. Kaddu-Mukasa, E. Ssekasanvu, E. Ddumba, D. Thomas and E.T. Katabira, "Rheumatic manifestations among HIV positive adults attending the Infectious Disease Clinic at Mulago Hospital", African Health Science, vol. 11(1), pp. 24-29, 2011.

[12] K. P. Liao and D.H. Solomon, "Traditional cardiovascular risk factors, inflammation and cardiovascular risk in rheumatoid arthritis", Rheumatology, vol. 52, pp. 45-52, 2013.

[13] J. J. Malemba, J. M. Mbuyi-Muamba, J. Mukaya, X. Bossuyt, M. P. Emonds, K. Deiteren and J. Muamba, "The phenotype and genotype of rheumatoid arthritis in the Democratic Republic of Congo", Arthritis Research Therapy, vol. 15(4), pp. 89-92, 2013.

[14] J. J. Malemba, J. Mbuyi-Muamba, J. Mukaya, X. Bossuyt, P. Verschueren, R. Westhovens and R.M. Campbell, "The epidemiology of rheumatoid arthritis in Kinshasa, Democratic Republic of Congoa population-based study", Rheumatology (Oxford), vol. 51(9), pp. 1644-1647, 2012.

[15] O. L. Meyers, S. Jessop, and P. Klemp, "The epidemiology of rheumatic disease in a rural and an urban population over the age of 65 years", South African Medicial Journal, vol. 62(12), pp. 403-405, 1982.

[16] J. D. Moolenburgh, H. A. Valkenburg, and P. B. Fourie, "A population study on rheumatoid arthritis in Lesotho, southern Africa", Annals of Rheumatologic Discussions, vol. 45(8), p. 691-695, 1986.

[17] K. Nishimura, D. Sugiyama, Y. Kogata, G. Tsuji, T. Nakazawa, S. Kawano \& S. Kumagai, "Meta-analysis: diagnostic accuracy of anticyclic citrullinated peptide antibody and rheumatoid factor for rheumatoid arthriti"s", Annals of Internal Medicine, vol. 146(11), pp. 797-808, 2007.

[18] B. Shah and A. Ankur, Harrison's Principles of Internal Medicine (18th edition), United States: McGraw Hill. 2012, p. 324-327.

[19] M. Singwe-Ngandeu, J. Meli, H. Ntsiba, C. Nouedoui, A. V. Yollo, M. B. Sida and D. Thomas, "Rheumatic diseases in patients attending a clinic at a referral hospital in Yaounde, Cameroon", Eastern Africa Medical Journal, vol. 84(9),pp. 404-409, 2007.

[20] S. Slimani and A. Ladjouze-Rezig, "Prevalence of rheumatoid arthritis in an urban population of Algeria: a prospective study", Rheumatology, vol. 53(3), pp. 571-573, 2014.

[21] J. S. Smolen, D. Aletaha and I. B. McInnes, "Rheumatoid arthritis", The Lancet, vol. 388(10055), pp. 2023-2038, 2016.

[22] D. H. Solomon, N. J. Goodson, J. N. Katz, M. E. Weinblatt, J. Avorn, and S.A. Setoguchi, "Patterns of cardiovascular risk in rheumatoid arthritis", Annals of the Rheumatic Diseases, vol. 65(12), pp. 16081612,2006

[23] L. Solomon, G. Robin and H.A. Valkenburg, "Rheumatoid arthritis in an urban South African Negro population" Annals of Rheumatologic Discussion, vol. 34(2), pp. 128-135, 1975.

[24] L. Solomon, H. A. Valkenburg, P. Beighton, G. Robin and C. L. Soskolne, "Rheumatic disorders in the South African Negro. Part I. Rheumatoid arthritis and ankylosing spondylitis", South African Medical Journal, vol. 49(32), pp. 1292-1296, 1975.

[25] O. M. Westwood, P. N. Nelson and F. C. Hay, "Rheumatoid factors: what's new?", Rheumatology, vol. 45(4), pp. 379-385, 2006.

[26] F. Wolfe, D. M. Mitchell, J. T. Sibley, J. F. Fries, D. A. Bloch, C. A Williams and M. A. Cathey, "The mortality of rheumatoid arthritis" Arthritis and Rheumatism, vol. 37(4), pp. 481-494, 1994. 